\title{
Serological and cellular non-responders in a long-term cross-sectional cohort of SARS-CoV-2-specific PCR-positive individuals
}

\author{
Giovanni Almanzar ${ }^{1}$, Charlotte Winzig ${ }^{1}$, Hanna Jury ${ }^{1}$, Eric Psota ${ }^{1}$, Timotheos \\ Christoforou $^{1}$, Johanna Block ${ }^{1}$, Sissy Sonnleitner ${ }^{2}$, and Martina Prelog ${ }^{1}$ \\ ${ }^{1}$ Universitatsklinikum Wurzburg Kinderklinik und Poliklinik \\ ${ }^{2}$ Department of Virology Medical Laboratory Dr Gernot Walder GmbH Ausservillgraten \\ Austria
}

September 29, 2021

\begin{abstract}
During the first pandemic wave, the dark figure of SARS-CoV-2 exposure was estimated to be high, however, an accelerated loss of antibodies was reported after about 6 months post infection. This study was performed to unveil the group of serological non-responders (NR) in PCR+ individuals 6-9 months after the first pandemic SARS-CoV-2 wave in spring 2020 and to evaluate their specific cellular immune response towards spike-molecule compared to PCR- and not PCR-tested (NT) household contact persons. SARS-CoV-2-specific antibodies were quantified using a commercial ELISA kit. The synergistic binding strength was assessed as relative avidity index (RAI) using ammonium-thiocyanate as chaotropic agent. The specific IFN $\gamma$-production in response to spike-protein was determined in spot-forming-units (SFU) by ELISPOT-assay. In PCR- 50.0\%, in PCR+ 35.3\% and in NT 20.7\% had undetectable IgG-anti-SARS-CoV-2 and were considered non-responders (NR). All seropositive responders from the PCR-, $45.5 \%$ of PCR+ and $43.0 \%$ of NT developed high avidity (RAI $>60 \%$ ). In serological responders, cellular responses were detected in $75.0 \%$ PCR-, $75.8 \% \mathrm{PCR}+$ and $66.7 \%$ NT. In serological NR, positive SFU were found in $75.0 \%$ PCR-, $22.2 \% \mathrm{PCR}+$ and $17.4 \%$ NT. Significantly higher stimulation-indices were seen in PCR+ responders compared to PCR+ serological NR. Our findings showed that also PCR- and household contact persons who were not tested (NT) developed SARS$\mathrm{CoV}-2$-specific humoral and cellular immune responses. The relatively large proportion of serological non-responders but also the proportion of cellular non-responders within the group of IgG-positive individuals after PCR+ infection underlines the need for COVID-19 vaccinations in the reconvalescent group.
\end{abstract}

\section{Introduction}

The coronavirus disease-19 (COVID-19) is caused by a virus called severe acute respiratory syndrome coronavirus 2 (SARS-CoV-2) (Zhou, Yang et al. 2020). The virus is a single-stranded RNA virus coding for major structural surface glycoproteins: spike $(\mathrm{S})$, matrix $(\mathrm{M})$, envelope $(\mathrm{E})$, and nucleoprotein $(\mathrm{N})$ and a set of 16 nonstructural proteins (NSPs) as well as several additional open reading frames encoding for accessory proteins involved in host-virus interactions (Bartlam, Yang et al. 2005). The S protein is a homotrimeric protein consisting of the functional domains $\mathrm{S} 1$ and $\mathrm{S} 2$ which are responsible for binding of the virus to the angiotensin converting enzyme-2 (ACE2) (Shang, Ye et al. 2020). Spread of the virus is done by person to person contact via airborne droplets and aerosols. Most of the infected persons develop mildly symptomatic disease such as fever, cough, dyspnea, fatigue headache, dysgusia, anosmia, rhinorrhoea, vomiting and diarrhea, while 10 to $30 \%$ of infected persons remain asymptomatic (Marian 2021).

Antibody production has been documented in patients with acute infection within 21 days post infection onset, whereas persons with mild symptoms have low or undetectable levels of antibodies (Long, Liu et al. 
2020, Long, Tang et al. 2020). T cell response has been investigated in COVID-19 patients after stimulation with $\mathrm{N}$ derived peptides using IFN $\gamma$-based enzyme-linked immunospots assays (IFN $\gamma$ ELISPOT assays) demonstrating circulation of $\mathrm{N}$-specific precursor cells in infected individuals. In contrast, low proportions of cells recognizing peptides derived from non-structural proteins (NSPs) were observed in those persons (Le Bert, Tan et al. 2020). Recently, preferential T helper cell type 1 (Th1) responses to S protein have been detected in patients with acute respiratory distress syndrome at early stages of the disease which increase over the time (Weiskopf, Schmitz et al. 2020).

The aim of this study was to evaluate the long-term humoral and cellular immune response to SARS-CoV2-S-protein comparing individuals PCR-positive or -negative for SARS-CoV-2 from the first pandemic wave with Wuhan type SARS-CoV-2 in spring 20206 to 9 months after infection. This study identifies a set of persons diagnosed with positive SARS-CoV-2 PCR that did not develop positive serological or cellular immune responses to SARS-CoV-2 and underlines the importance to appeal to all reconvalescent individuals to get COVID-19 vaccination.

\section{Material and Methods}

\section{Volunteers}

Peripheral venous blood was collected from 88 volunteers enrolled in this observational cross-sectional study classified according to a previous COVID-19 diagnosis determined by PCR test for SARS-CoV-2 or household contact persons to PCR-tested persons which were not tested despite exposure from a previously published cohort of the first pandemic wave in spring 2020 by Wuhan type SARS-CoV-2 (Sonnleitner, Prelog et al. 2021). Blood samples were obtained between July 2020 and December 20206 to 9 months post infection or contacts in the area of East Tyrol, Austria, and the city area of Wuerzburg, Bavaria, Germany. Eight were PCR negative (PCR-), 51 were PCR positive (PCR+), and 29 were not PCR-tested (NT) who had household contact with SARS-CoV-2 infected PCR+ persons (Table 1). Symptomatic persons reported at least one symptom of the infection including headache, cough, temperature $>38.5^{\circ} \mathrm{C}$, fatigue or anosmia. All participants gave their written informed consent according to the principles of the declaration of Helsinski 2013 and ethical approval of the committee at the University of Wuerzburg (Protocol number 20201105_01).

Peripheral mononuclear blood cells (PBMCs) were isolated by density centrifugation (FicoLite-H, Linaris, Wertheim, Germany) according to standardized laboratory procedures and preserved in liquid nitrogen, while serum samples were preserved at $-20^{\circ} \mathrm{C}$ until use.

\section{SARS-CoV-2 IgG and IgA ELISA}

Serum IgG or IgA antibodies against SARS-CoV-2 were determined in serum samples by enzyme linked immunosorbent assay ELISA according to the manufacturer (agile SARS-CoV-2 IgG ELISA, Virion/Serion, Wuerzburg, Germany) given a sensitivity of $96.2 \%$ and a specificity of $100 \%$ (Stromer, Rose et al. 2020). IgG and IgA concentrations were positive for values [?]15U/mL and $14 \mathrm{U} / \mathrm{mL}$, respectively. Individuals with IgG concentrations below $15 \mathrm{U} / \mathrm{mL}$ were considered as non-responders and analyzed independently. $\operatorname{IgA}$ concentrations were determined in IgG positive samples only.

\section{IgG-anti-SARS-CoV-2 Avidity}

IgG avidity was used as a surrogate marker for synergistic antibody-antigen-binding and IgG maturation during clonal hypermutation of specific memory B cells over time. The IgG-anti-SARS-CoV-2 avidity was determined in IgG positive samples by adaptation of the agile IgG-SARS-CoV-2 ELISA (Virion/Serion) evaluating the remaining bound $\mathrm{IgG}$ after incubation with $1 \mathrm{M}$ ammonium thiocyanate $\left(\mathrm{NH}_{4} \mathrm{SCN}\right)$ and using PBS as reference (Almanzar, Ottensmeier et al. 2013) and was performed in duplicates. The relative avidity index (RAI) was determined in serum samples at an O.D. equivalent for $100 \mathrm{U} / \mathrm{mL}$ and calculated as follows: the IgG-anti-SARS-CoV-2 concentrations after $\mathrm{NH}_{4} \mathrm{SCN} /$ the IgG-anti-SARS-CoV-2 concentrations after PBS multiplied by 100 . RAI values were considered as: RAI $>60 \%$ high avidity, $40 \%$ [?] RAI [?] $60 \%$ as moderate, and RAI $<40 \%$ as low avidity according to experience with varicella-specific avidities (Kneitz, Schubert et al. 2004). 


\section{IFN $\gamma$ ELISPOT}

SARS-CoV-2-specific $\mathrm{T}$ cell response was determined by using an IFN $\gamma$ ELISPOT assay after stimulation of $4 \times 10^{5}$ PBMCs in the presence of $10 \mu \mathrm{g} / \mathrm{mL}$ SARS antigen (Ag) (SARS-CoV-2 Spike Ectodomain (S1-S2), Virion/Serion) and $2 \mu \mathrm{g} / \mathrm{mL}$ measles virus lysate (Virion/Serion) as a specific positive control for $18 \mathrm{~h}$ at $37^{\circ}$ $\mathrm{C}$ and was performed in triplicates. One hundred $\mathrm{ng} / \mathrm{mL}$ phytohemagglutinin A (PHA, Sigma, Taufkirchen, Germany) and X-VIVO ${ }^{\text {TM}}-20$ medium (Lonza, Verviers, Belgium) were used as positive and negative controls, respectively. Briefly, a preactivated 96-well plate (Milipore, Merck, Darmstadt, Germany) plate was coated with $5 \mu \mathrm{g} / \mathrm{mL}$ anti-IFN $\gamma$ (clone 1-D1K, Mabtech, Nacka Strand, Sweden) in PBS O.N. at $4^{\circ} \mathrm{C}$. Unspecific binding sites were blocked with 5\% BSA/PBS (Miltenyi Biotec, Bergisch Gladbach, Germany) for $1 \mathrm{~h}$ at $37^{\circ}$ C. Detection of IFN $\gamma$ was performed after incubation with $2 \mu \mathrm{g} / \mathrm{mL}$ of biotinylated anti-IFN $\gamma$ (clone 7-b6-1, Mabtech) in $0.5 \% \mathrm{BSA} / \mathrm{PBS}$ for $1 \mathrm{~h}$ at room temperature (RT). Spot development was done after incubation with BCIP/NBT plus (Mabtech). Spot forming units (SFU) were quantified by C.T.L. ELISPOT reader software (Bonn, Germany) and expressed as SFU $/ 10^{6}$ cells. An arbitrary limit of $<20 \mathrm{SFU} / 10^{6}$ cells was set as negative, as determined by pilot experiments with defined positive samples. Data were normalized by calculating the stimulation index (SI) as follows: the number of SFU $/ 10^{6}$ antigen divided SFU $/ 10^{6}$ negative control. Positive T cell reactivity to SARS-CoV-2 was considered for SI values above 1.04 as determined by pilot experiments with defined negative samples.

\section{Statistics}

After testing for distribution with Komolgorov-Smirnov-test, non-parametric variables were compared by the Mann-Whitney U-test using SPSS software (Version 26.0) (IBM statistic, Chicago USA). Correlations between demographic and immunological parameters were performed using Spearman rank's correlation coefficient. Numbers of stratified groups were compared using $\mathrm{X}^{2}$ or Fisher's exacta test. A p-value [?] 0.05 was considered statistically significant.

\section{Results}

High proportions of serological non-responders in the PCR + group and high proportions of serological responders in the PCR- and NT contact group

In PCR+, 18 persons were serological non-responders (35.3\%) at the time point of serum sampling. In contrast, 4 persons were serologically positive in the PCR- group (50.0\%) and 23 persons $(79.3 \%)$ in the group of contact persons who were not tested by PCR (NT) (Figure 1A).

Antibody avidity was assessed as a surrogate marker of the synergistic antibody-antigen-binding strength and affinity maturation of SARS-CoV-2-specific memory B cells by clonal hypermutation over time. In 4 (100\%) PCR- individuals, in 15 (45.5\%) PCR+ and in 3 (43.0\%) NT high RAI were found, whereas in 8 (24.0\%) PCR+ and in $4(57.0 \%)$ NT low RAI were found (Figure 1B).

IgA, the predominant antibody class in external secretions and the second secreted antibody in serum, plays an important role in immune protection defending mucosal surfaces such as the linings of the respiratory, gastrointestinal, and genitourinary tracts from pathogens (Woof and Kerr 2006) and was investigated as a surrogate marker for mucosal immunoglobulins against SARS-CoV-2 in IgG positive individuals. Positive IgA concentrations above the detection limit were found in 1 (25.0\%) PCR- person of the IgG responders, in $20(60.6 \%)$ of PCR+ and in $3(50.0 \%)$ of NT persons (Figure $2 \mathrm{~A})$. IgA and IgG concentrations correlated with each other (Figure 2B).

\section{Serological responders are able to develop positive cellular reactivity towards SARS-CoV-2} spike molecule

Serological non-responders with IgG concentrations below the detection limit of the ELISA system (NR) were analyzed separately (Table 2). No significant difference was found between NR and serological responders regarding age and sex distribution or the number of asymptomatic or symptomatic infections. 
In serological responders, 1 of $4(25.0 \%)$ of PCR- individuals, in 8 of $33(24.2 \%)$ of PCR + and in 1 of 6 $(16.7 \%)$ NT had SFU $<20$ (Figure 3A, C). In serological responders, $3(75.0 \%)$ of PCR-, $25(75.8 \%)$ of PCR+ and $5(83.3 \%)$ of NT developed positive SFU, whereas in the NR group positive SFU were found in 3 of 4 (75.0\%) of PCR-, in 7 of $18(38.9 \%)$ of PCR + and in 6 of $23(26.1 \%)$ of NT.

In serological responders, the SI was negative in $1(25.0 \%)$ of PCR-, in $7(21.2 \%)$ of PCR+ and in $1(16.7 \%)$ NT (Figure 3B). A positive SI was developed in $3(75.0 \%)$ of PCR-, in $26(78.8 \%)$ of PCR + and in $5(83.3 \%)$ of NT. In the NR group, 1 of 4 (25.0\%) of PCR- (not significant compared to serological responders), 6 of $18(33.3 \%)$ of PCR $+(\mathrm{p}<0.001)$ and 6 of $23(26.1 \%)$ of NT developed positive SI $(\mathrm{p}<0.001)$.

Significantly higher SI were found in PCR + responders compared to PCR+ NR, as well as in NT responders compared to NT NR (Figure 3A, B). No correlation could be found between IgG concentrations and cellular reactivity. No correlation was seen between age and parameters of humoral or cellular immune responses.

\section{Discussion}

The study was performed to unveil the group of serological non-responders in PCR+ individuals of the first pandemic wave with Wuhan type SARS-CoV-2 in spring 20206 to 9 months after diagnosis and to evaluate their specific cellular immune response towards spike molecule compared to two groups of PCR- and of not PCR-tested (NT) household contact persons. The present study revealed a large group of serological non-responders (NR) in PCR+ persons after 6 to 9 months post infection, and in contrast, determined a SARS-CoV-2-specific serologically positive and cellular reactive group of individuals in PCR- contact persons and in household contact persons who were not PCR-tested.

Our results are in concordance with previous studies showing that SARS-CoV-2 infected persons are able to develop a robust antibody response particularly in symptomatic persons (Zhang, Li et al. 2020, Sonnleitner, Prelog et al. 2021). However, we could refer to a group of serological non-responders of $35.3 \%$ in the PCR+ group, which concurs to previous studies that showed that donors, especially with milder symptoms, middleaged, and without comorbidities failed to have or had low levels of IgG-anti-SARS-CoV-2 antibodies (Baron, Risch et al. 2020, Marklund, Leach et al. 2020).

Interestingly, in the majority of IgG positive persons and particularly in those who were tested PCR+, positive serum IgA concentrations were still present over 6 months post diagnosis. The IgA concentrations correlated well with the IgG concentrations, and underline the observation that those individuals who develop a significant IgG response likely maintain positive serum IgA levels. IgA is one of the first line of defense against infection and has an important role mediating adaptive humoral response protecting mucosal surfaces (Devito, Hinkula et al. 2000, Planque, Salas et al. 2010). Recently, a group demonstrated that early response to SARS-CoV-2 is dominated by IgA antibodies with higher neutralizing capacity than IgG in the first weeks post infection. Moreover, the study also showed that IgA serum concentrations are diminished after one month of infection onset (Sterlin, Mathian et al. 2021). Undetectable IgA concentrations in some donors from the PCR- and NT group with positive IgG may be explained by possibly shortened periods of viral shedding (Callow 1985). The fact that IgA has a production peak approximately 10 days after mucosal antigen contact (Moldoveanu, Clements et al. 1995) suggest that time of collection of the samples for the analysis of the IgA response in the cohort studied is an important factor to be considered. However, our results suggest that IgA can persist even several months after primary SARS-CoV-2 infection.

A surrogate marker for the binding capacity was the assessment of IgG avidity in IgG positive individuals. As known from serological measures against other infectious pathogens, the IgG avidity matures within the first 3 to 5 months after primary infection due to clonal hypermutation of memory B cells (Prelog, Almanzar et al. 2013, Prelog, Schonlaub et al. 2013). Moderate to high RAI was developed in most of serologically responding PCR+ individuals. Although the neutralizing ability of the IgG was not tested in this study, this finding suggests a high binding strength of the detected IgG in those individuals with potentially neutralizing activity. A subgroup of the cohort was tested by neutralization assays in a former study at 5 months post positive PCR and 29 of 34 (85.3\%) showed positive results in an enzyme-linked neutralization assays previously published (Sonnleitner, Prelog et al. 2021). In addition, the IgG ELISA 
assay used to analyze the concentration of IgG towards SARS-CoV-2 showed a highly significant correlation with neutralizing antibodies (Stromer, Rose et al. 2020).

Inflammation may occur during virus infection resulting in recruitment of CD4+ and CD8+ T cells and the production of pro-inflammatory cytokines such as IFN $\gamma$ or TNF $\alpha$. The subsequent generation of virusspecific $\mathrm{T}$ cells that are in charge of the elimination of the infection is as important as the generation of specific antibodies for the control of the infection and long-term neutralizing immunity. The present study identifies serological non-responders who were able to mount a cellular immune response, although to a significant lower level than found in individuals with positive IgG concentrations. Also, individuals of the PCR- and NT group developed positive cellular responses. These findings support the results by others who showed that unexposed or serologically negative donors have a mixed SARS-CoV-2-specific IFNr response to nucleoprotein or to non-structural protein (NSP) 7 and NSP13 (Grifoni, Weiskopf et al. 2020, Le Bert, Tan et al. 2020).

One of the most astonishing results was that serological and cellular reactive samples could be identified in the PCR- and in the non-tested household contact groups. Although IgG responses in the PCR- and in the NT groups were lower compared to PCR + group, avidities were fairly good and positive IgA levels could be found. The cellular responses were equal to PCR+ individuals. Thus, the present study underlines the impact of undetected SARS-CoV-2 during the first pandemic wave in spring 2020 by Wuhan type.

This cohort study is limited by its cross-sectional character, which does not allow to describe antibody dynamics over time and the relatively small sample size and the geographic locations. Study participants were not investigated regarding the disease severity, underlying diseases, COVID-19 risk factors or specific treatments and are highly heterogeneous regarding their age. However, no correlations with age could be demonstrated regarding humoral and cellular immune parameters. As the initial antibody and cellular response shortly after the infection is not known in our cohort, it is difficult to allow prognosis on the further dynamics of the humoral and cellular immune response in the study participants. A subgroup of our study participants showed positive IgG antibodies against S1/S2 domain with a CLIA assay in 28 of 34 individuals $(82.4 \%)$ after about one month post infection and 27 (81.8\%) after 5 months (Sonnleitner, Prelog et al. 2021). Several studies showed that most individuals with positive antibody reactions shortly after infection maintain their antibodies; however, a sharp decrease is reported after 6 months (Jaaskelainen, Ahava et al. 2021, Pradenas, Trinite et al. 2021), which may explain the relatively large number of serological nonresponders in our cohort. These results underline the need for immunological booster after at least 6 months post infection. A booster by vaccination could be shown in reconvalescent individuals by several groups (Tretyn, Szczepanek et al. 2021) .

In conclusion, our findings showed that individuals who were tested negative for SARS-CoV-2 in PCR and individuals who were not tested (NT) although they were household contact persons to PCR+ persons developed SARS-CoV-2-specific humoral and cellular immune responses. The relatively large proportion of serological non-responders but also the proportion of cellular non-responders within the group of IgG positive individuals after PCR + SARS-CoV-2 infection at least 6 months ago underlines the need for COVID19 vaccinations in the reconvalescent group. Thus, the present study provides further evidence for the recommendation to vaccinate reconvalescent individuals from the first pandemic wave after at least 6 months post positive PCR to boost their humoral and cellular immune response.

\section{Conflict of interest}

The authors declare no conflicts of interest

\section{Ethical approval}

The studies involving human participants were reviewed and approved by the ethics committee at the University of Wuerzburg, protocol number 20201105_01. The patients/participants provided their written informed consent to participate in this study.

\section{Acknowledgements}


The project was funded by the Bavarian Futur Bonus Programm 253/WÜR

\section{References}

1. Almanzar, G., B. Ottensmeier, J. Liese and M. Prelog (2013). Assessment of IgG avidity against pertussis toxin and filamentous hemagglutinin via an adapted enzyme-linked immunosorbent assay (ELISA) using ammonium thiocyanate. J Immunol Methods 387(1-2): 36-42.DOI: 10.1016/j.jim.2012.09.008.

2. Baron, R. C., L. Risch, M. Weber, S. Thiel, K. Grossmann, N. Wohlwend, T. Lung, D. Hillmann, M. Ritzler, S. Bigler, K. Egli, F. Ferrara, T. Bodmer, M. Imperiali, S. Heer, H. Renz, L. Flatz, P. Kohler, P. Vernazza, C. R. Kahlert, M. Paprotny and M. Risch (2020). Frequency of serological non-responders and false-negative RT-PCR results in SARS-CoV-2 testing: a population-based study. Clin Chem Lab Med58(12): 2131-2140.DOI: 10.1515/cclm-2020-0978.

3. Bartlam, M., H. Yang and Z. Rao (2005). Structural insights into SARS coronavirus proteins. Curr Opin Struct Biol 15(6): 664-672.DOI: 10.1016/j.sbi.2005.10.004.

4. Callow, K. A. (1985). Effect of specific humoral immunity and some non-specific factors on resistance of volunteers to respiratory coronavirus infection. J Hyg (Lond) 95(1): 173-189.DOI: $10.1017 / \mathrm{s} 0022172400062410$.

5. Devito, C., J. Hinkula, R. Kaul, L. Lopalco, J. J. Bwayo, F. Plummer, M. Clerici and K. Broliden (2000). Mucosal and plasma IgA from HIV-exposed seronegative individuals neutralize a primary HIV-1 isolate. AIDS 14(13): 1917-1920.DOI: 10.1097/00002030-200009080-00006.

6. Grifoni, A., D. Weiskopf, S. I. Ramirez, J. Mateus, J. M. Dan, C. R. Moderbacher, S. A. Rawlings, A. Sutherland, L. Premkumar, R. S. Jadi, D. Marrama, A. M. de Silva, A. Frazier, A. F. Carlin, J. A. Greenbaum, B. Peters, F. Krammer, D. M. Smith, S. Crotty and A. Sette (2020). Targets of T Cell Responses to SARS-CoV-2 Coronavirus in Humans with COVID-19 Disease and Unexposed Individuals. Cell 181(7): 1489-1501 e1415.DOI: 10.1016/j.cell.2020.05.015.

7. Jaaskelainen, A. E., M. J. Ahava, P. Jokela, L. Szirovicza, S. Pohjala, O. Vapalahti, M. Lappalainen, J. Hepojoki and S. Kurkela (2021). Evaluation of three rapid lateral flow antigen detection tests for the diagnosis of SARS-CoV-2 infection. J Clin Virol 137: 104785.DOI: 10.1016/j.jcv.2021.104785.

8. Kneitz, R. H., J. Schubert, F. Tollmann, W. Zens, K. Hedman and B. Weissbrich (2004). A new method for determination of varicella-zoster virus immunoglobulin $\mathrm{G}$ avidity in serum and cerebrospinal fluid.BMC Infect Dis 4: 33.DOI: 10.1186/1471-2334-4-33.

9. Le Bert, N., A. T. Tan, K. Kunasegaran, C. Y. L. Tham, M. Hafezi, A. Chia, M. H. Y. Chng, M. Lin, N. Tan, M. Linster, W. N. Chia, M. I. Chen, L. F. Wang, E. E. Ooi, S. Kalimuddin, P. A. Tambyah, J. G. Low, Y. J. Tan and A. Bertoletti (2020). SARS-CoV-2-specific T cell immunity in cases of COVID-19 and SARS, and uninfected controls.Nature 584(7821): 457-462.DOI: 10.1038/s41586-020-2550-z.

10. Long, Q. X., B. Z. Liu, H. J. Deng, G. C. Wu, K. Deng, Y. K. Chen, P. Liao, J. F. Qiu, Y. Lin, X. F. Cai, D. Q. Wang, Y. Hu, J. H. Ren, N. Tang, Y. Y. Xu, L. H. Yu, Z. Mo, F. Gong, X. L. Zhang, W. G. Tian, L. Hu, X. X. Zhang, J. L. Xiang, H. X. Du, H. W. Liu, C. H. Lang, X. H. Luo, S. B. Wu, X. P. Cui, Z. Zhou, M. M. Zhu, J. Wang, C. J. Xue, X. F. Li, L. Wang, Z. J. Li, K. Wang, C. C. Niu, Q. J. Yang, X. J. Tang, Y. Zhang, X. M. Liu, J. J. Li, D. C. Zhang, F. Zhang, P. Liu, J. Yuan, Q. Li, J. L. Hu, J. Chen and A. L. Huang (2020). Antibody responses to SARS-CoV-2 in patients with COVID-19. Nat Med 26(6): 845-848.DOI: 10.1038/s41591-020-0897-1.

11. Long, Q. X., X. J. Tang, Q. L. Shi, Q. Li, H. J. Deng, J. Yuan, J. L. Hu, W. Xu, Y. Zhang, F. J. Lv, K. Su, F. Zhang, J. Gong, B. Wu, X. M. Liu, J. J. Li, J. F. Qiu, J. Chen and A. L. Huang (2020). Clinical and immunological assessment of asymptomatic SARS-CoV-2 infections.Nat Med 26(8): 12001204.DOI: 10.1038/s41591-020-0965-6.

12. Marian, A. J. (2021). Current state of vaccine development and targeted therapies for COVID-19: impact of basic science discoveries. Cardiovasc Pathol 50: 107278.DOI: 10.1016/j.carpath.2020.107278.

13. Marklund, E., S. Leach, H. Axelsson, K. Nystrom, H. Norder, M. Bemark, D. Angeletti, A. Lundgren, S. Nilsson, L. M. Andersson, A. Yilmaz, M. Lindh, J. A. Liljeqvist and M. Gisslen (2020). SerumIgG responses to SARS-CoV-2 after mild and severe COVID-19 infection and analysis of IgG nonresponders. PLoS One 15(10): e0241104.DOI: 10.1371/journal.pone.0241104. 
14. Moldoveanu, Z., M. L. Clements, S. J. Prince, B. R. Murphy and J. Mestecky (1995). Human immune responses to influenza virus vaccines administered by systemic or mucosal routes. Vaccine 13(11): 1006-1012.DOI: 10.1016/0264-410x(95)00016-t.

15. Planque, S., M. Salas, Y. Mitsuda, M. Sienczyk, M. A. Escobar, J. P. Mooney, M. K. Morris, Y. Nishiyama, D. Ghosh, A. Kumar, F. Gao, C. V. Hanson and S. Paul (2010). Neutralization of genetically diverse HIV-1 strains by IgA antibodies to the gp120-CD4-binding site from long-term survivors of HIV infection. AIDS 24(6): 875-884.DOI: 10.1097/QAD.0b013e3283376e88.

16. Pradenas, E., B. Trinite, V. Urrea, S. Marfil, C. Avila-Nieto, M. L. Rodriguez de la Concepcion, F. Tarres-Freixas, S. Perez-Yanes, C. Rovirosa, E. Ainsua-Enrich, J. Rodon, J. Vergara-Alert, J. Segales, V. Guallar, A. Valencia, N. Izquierdo-Useros, R. Paredes, L. Mateu, A. Chamorro, M. Massanella, J. Carrillo, B. Clotet and J. Blanco (2021). Stable neutralizing antibody levels 6 months after mild and severe COVID-19 episodes. Med (N Y) 2(3): 313-320 e314.DOI: 10.1016/j.medj.2021.01.005.

17. Prelog, M., G. Almanzar, N. Rieber, B. Ottensmeier, M. Zlamy and J. Liese (2013). Differences of IgG antibody avidity after an acellular pertussis (aP) booster in adolescents after a whole cell (wcP) or aP primary vaccination. Vaccine 31(2): 387-393.DOI: 10.1016/j.vaccine.2012.10.105.

18. Prelog, M., J. Schonlaub, V. Jeller, G. Almanzar, K. Hofner, S. Gruber, T. Eiwegger and R. Wurzner (2013). Reduced varicella-zoster-virus (VZV)-specific lymphocytes and IgG antibody avidity in solid organ transplant recipients. Vaccine 31(20): 2420-2426.DOI: 10.1016/j.vaccine.2013.03.058.

19. Shang, J., G. Ye, K. Shi, Y. Wan, C. Luo, H. Aihara, Q. Geng, A. Auerbach and F. Li (2020). Structural basis of receptor recognition by SARS-CoV-2. Nature 581(7807): 221-224.DOI: 10.1038/s41586-0202179-y.

20. Sonnleitner, S. T., M. Prelog, B. Jansen, C. Rodgarkia-Dara, S. Gietl, C. M. Schonegger, S. Koblmuller, C. Sturmbauer, W. Posch, G. Almanzar, H. Jury, T. Loney, A. Tichy, N. Nowotny and G. Walder (2021). Maintenance of neutralizing antibodies over ten months in convalescent SARS-CoV-2 afflicted patients. Transbound Emerg Dis .DOI: 10.1111/tbed.14130.

21. Sterlin, D., A. Mathian, M. Miyara, A. Mohr, F. Anna, L. Claer, P. Quentric, J. Fadlallah, H. Devilliers, P. Ghillani, C. Gunn, R. Hockett, S. Mudumba, A. Guihot, C. E. Luyt, J. Mayaux, A. Beurton, S. Fourati, T. Bruel, O. Schwartz, J. M. Lacorte, H. Yssel, C. Parizot, K. Dorgham, P. Charneau, Z. Amoura and G. Gorochov (2021). IgA dominates the early neutralizing antibody response to SARSCoV-2.Sci Transl Med 13(577).DOI: 10.1126/scitranslmed.abd2223.

22. Stromer, A., R. Rose, O. Grobe, F. Neumann, H. Fickenscher, T. Lorentz and A. Krumbholz (2020). Kinetics of Nucleo- and Spike Protein-Specific Immunoglobulin G and of Virus-Neutralizing Antibodies after SARS-CoV-2 Infection. Microorganisms 8(10).DOI: 10.3390/microorganisms8101572.

23. Tretyn, A., J. Szczepanek, M. Skorupa, J. Jarkiewicz-Tretyn, D. Sandomierz, J. Dejewska, K. Ciechanowska, A. Jarkiewicz-Tretyn, W. Koper and K. Palgan (2021). Differences in the Concentration of Anti-SARS-CoV-2 IgG Antibodies Post-COVID-19 Recovery or Post-Vaccination. Cells 10(8).DOI: $10.3390 /$ cells10081952.

24. Weiskopf, D., K. S. Schmitz, M. P. Raadsen, A. Grifoni, N. M. A. Okba, H. Endeman, J. P. C. van den Akker, R. Molenkamp, M. P. G. Koopmans, E. C. M. van Gorp, B. L. Haagmans, R. L. de Swart, A. Sette and R. D. de Vries (2020). Phenotype and kinetics of SARS-CoV-2-specific T cells in COVID-19 patients with acute respiratory distress syndrome.Sci Immunol 5(48).DOI: 10.1126/sciimmunol.abd2071.

25. Woof, J. M. and M. A. Kerr (2006). The function of immunoglobulin A in immunity. J Pathol 208(2): 270-282.DOI: $10.1002 /$ path.1877.

26. Zhang, Y., Y. Li, L. Wang, M. Li and X. Zhou (2020). Evaluating Transmission Heterogeneity and Super-Spreading Event of COVID-19 in a Metropolis of China. Int J Environ Res Public Health17(10).DOI: 10.3390/ijerph17103705.

27. Zhou, P., X. L. Yang, X. G. Wang, B. Hu, L. Zhang, W. Zhang, H. R. Si, Y. Zhu, B. Li, C. L. Huang, H. D. Chen, J. Chen, Y. Luo, H. Guo, R. D. Jiang, M. Q. Liu, Y. Chen, X. R. Shen, X. Wang, X. S. Zheng, K. Zhao, Q. J. Chen, F. Deng, L. L. Liu, B. Yan, F. X. Zhan, Y. Y. Wang, G. F. Xiao and Z. L. Shi (2020). A pneumonia outbreak associated with a new coronavirus of probable bat origin. Nature 
579(7798): 270-273.DOI: 10.1038/s41586-020-2012-7.

\section{Hosted file}

Figures_Almanzar_2021.pptx available at https://authorea.com/users/382397/articles/539748serological-and-cellular-non-responders-in-a-long-term-cross-sectional-cohort-of-sarscov-2-specific-pcr-positive-individuals

\section{Hosted file}

Tables_Almanzar_2021.docx available at https://authorea.com/users/382397/articles/539748serological-and-cellular-non-responders-in-a-long-term-cross-sectional-cohort-of-sarscov-2-specific-pcr-positive-individuals 